\title{
Micronutrient powder distribution through Maternal, Neonatal and Child Health Weeks in Nigeria: process evaluation of feasibility and use
}

\author{
Eline L Korenromp ${ }^{1,2, *}$, Opeyemi Adeosun ${ }^{3}$, Femi Adegoke $^{3}$, Adekunle Akerele ${ }^{3}$, \\ Catherine Anger ${ }^{4}$, Chimere Ohajinwa ${ }^{5}$, Christine Hotz ${ }^{1}$, Larry Umunna ${ }^{5}$ and \\ Francis Aminu 5 \\ ${ }^{1}$ Global Alliance for Improved Nutrition, Rue de Vermont 37-39/PO Box 55, CH-1211 Geneva, Switzerland: \\ ${ }^{2}$ Avenir Health, 1 route de Morillons/150 Route de Ferney (WCC, Office 164), PO Box 2100, CH-1211 Geneva 2, \\ Switzerland: ${ }^{3}$ Binomial Optimus Ltd, Abuja, Nigeria: ${ }^{4}$ Benue State Ministry of Health, Makurdi, Nigeria: \\ ${ }^{5}$ Global Alliance for Improved Nutrition, Abuja, Nigeria
}

Submitted 26 February 2015: Final revision received 7 June 2015: Accepted 14 July 2015: First published online 15 September 2015

\begin{abstract}
Objective: To determine the feasibility of distributing micronutrient powders (MNP) for home fortification during biannual Maternal, Neonatal and Child Health Week (MNCHW) events, as a strategy to improve young child nutrition.

Design: We evaluated the coverage, delivery, use and adherence of MNP, and associated behaviour change communication (BCC) materials and social mobilization, through cross-sectional surveys of caregivers attending healthservice distribution events and health workers involved in MNP distribution, facility-based observations of MNP distribution activities and a repeated survey of caregivers in their homes who received MNP for their child.

Setting: Four Local Government Areas in Benue State, Nigeria.

Subjects: Caregivers of children 6-59 months of age attending health-service distribution events.

Results: The 8 million MNP delivered in this pilot during three distribution events were estimated to reach about one-third of eligible children in the area at each event. Programme fidelity was limited by shortages of MNP, BCC materials and inadequate social mobilization, with some limitations in health worker training and engagement. MNP use was consistent with the recommended two or three sachets per week among 51-69\% of caregivers surveyed at home.

Conclusions: MNP coverage was low, but consistent with that typically achieved with other services delivered through MNCHW in Benue. Among caregivers who received MNP, acceptance and use among targeted children was high. While some weaknesses in knowledge and delivery of MNP by health workers were observed, health system strengthening and more extensive social mobilization would be key to achieving higher coverage with $\mathrm{MNP}$ and other health services provided through MNCHW.
\end{abstract}

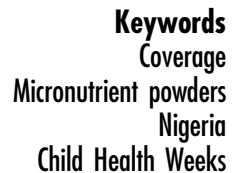

Multiple micronutrient powders (MNP) are a proven home-fortification strategy recommended by the WHO to improve micronutrient intakes and reduce anaemia and $\mathrm{Fe}$ deficiency in children aged 6-23 months. This population group is particularly vulnerable to malnutrition, as breast milk is complemented with locally available solid foods that often fail to meet nutrient requirements ${ }^{(1)}$. A Cochrane review of controlled trials conducted in-low income populations in Asia, Africa and the Caribbean estimated that daily home fortification of complementary foods with
MNP reduces aneamia by $31 \%$ and Fe deficiency by $51 \%$ in children aged 6-23 months ${ }^{(2)}$.

While the efficacy of MNP in improving micronutrient intakes and nutritional status of young children is proven, it is less clear which delivery channels are most effective and cost-effective for wide-scale implementation based on the local health system and socio-economic context ${ }^{(3)}$. Good MNP uptake, use and nutritional effectiveness have been observed with distribution by community vendors supported by social marketing in Kenya ${ }^{(4)}$, with commercial 
sales supported by public advocacy in China ${ }^{(5)}$, and with clinic- and home-based distribution through the Integrated Child Development Services in India ${ }^{(6)}$. Biannual campaigns (e.g. Child Health Weeks) have been used widely across Africa in particular to deliver intermittent on-site health services to children under 5 years of age, such as vaccines, high-dose vitamin A supplements and deworming medication $^{(7)}$; however, this mechanism has not yet been evaluated for its usefulness to deliver home fortification products such as MNP.

In Nigeria, the federal government and state governments aim to use MNP as part of a strategy to improve infant and young child feeding (IYCF) ${ }^{(8)}$. In 2013, Nigeria's National Council on Health approved revised guidelines for controlling micronutrient deficiencies ${ }^{(9)}$. Following this, Benue State in Nigeria's North-Central zone was the first state to launch a home fortification programme. With support from the Global Alliance for Improved Nutrition (GAIN), it piloted distribution of State Ministry of Health-procured MNP through the existing, publicly funded platform of Maternal, Neonatal and Child Health Weeks (MNCHW) which, at 6-month intervals, delivers a comprehensive package of high-impact, low-cost services to women, infants and children under 5 years ${ }^{(8)}$. Since in Nigeria MNCHW have consistently achieved higher coverage than routine health services, including antenatal care, family planning, immunization, preventive and curative primary health services, and health promotion, this is a promising channel to also deliver MNP to large numbers of mothers and children.

Theoretically, when adding MNP distribution to an existing health-service delivery package, the coverage should be similar to that attained for other services. However, there is some concern that additional services may overburden both service providers and participating child caregivers and hence increase the risk of declines in coverage or quality of service delivery ${ }^{(7)}$. Further, MNP are to be used at home, thus requiring that information, motivation and skills for their appropriate use be adequately delivered, received, understood and accepted by caregivers during the event.

The aim of the present study was to evaluate the feasibility of distributing MNP through MNCHW in Nigeria using a process evaluation framework. The specific objectives were to: (i) estimate coverage with MNP among children aged 6-59 months; (ii) assess quality of programme delivery through health workers' knowledge and counselling capacity regarding IYCF and MNP-based home fortification; (iii) estimate MNP acceptability, use and adherence for the primary target group of children aged 6-23 months; and (iv) identify barriers and facilitating factors for MNP use.

\section{Methods}

We conducted a process evaluation study of a pilot programme to add MNP delivery, and supporting behaviour change communication (BCC) materials and social mobilization, to well-established MNCHW during two events, in December 2013 (MNCHW-Dec-13) and June 2014 (MNCHW-June-14), in Benue State, Nigeria. The process evaluation plan was adapted from a framework for assessing the implementation of health promotion programmes and focused on aspects of recruitment, fidelity, dose delivered, dose received and context ${ }^{(10)}$.

\section{Pilot programme on micronutrient powders}

\section{Context and location}

The biannual MNCHW events provide a comprehensive package of services for infants and children under 5 years of age and for pregnant and lactating women ${ }^{(8)}$. Of twenty-three Local Government Areas participating in Benue's MNCHW, five that had been affected by floods and communal crises along the Benue River in July to September 2013 were selected by the State Ministry of Health for MNP distribution, in view of their increased nutritional vulnerability and potential benefit from the programme. The guidelines, training packages and communications materials for the MNP pilot programme as part of the MNCHW were developed by the Benue State Ministry of Health.

\section{Production and procurement of micronutrient powders}

Single-dose, fifteen-micronutrient, $1 \mathrm{~g}$ MNP sachets were procured from a Nigerian pharmaceutical company, Bio-Organic Nutrient System Limited, which launched MNP production in Lagos under the brand name 'Enrich' (http://bioorganicsng.com/enrich-product/). An independent evaluation in 2013 attested to the satisfactory production of the MNP sachets, with recommendations on packaging, minor product reformulation and formalization of quality control being implemented by the producer prior to the pilot ${ }^{(11)}$.

MNP procurement was based on the distribution of sixty sachets to each child 6-59 months of age anticipated to attend the MNCHW. Through this delivery channel, the pilot aimed to reach $50 \%$ of resident children aged 6-59 months with MNP and supporting BCC materials. For the MNCHW-Dec-13, however, only 3 million of the planned 5.5 million sachets were delivered, of which a part arrived shortly before the start of the MNCHW. For the subsequent distributions supply of MNP was complete, given the longer lead time for their production.

\section{Distribution plan}

In December 2013, all distribution occurred at health centres operating MNCHW. To compensate for the initial shortage in MNP supply, distribution was rationed to thirty sachets per child, with priority to children aged 6-23 months. Also, an additional distribution was arranged 3 months later through Immunization Plus Days held in March 2014 (IPD-Mar-14), during which children aged 
0-59 months receive polio and other vaccines at home, at health facilities or at fixed posts within communities. At the MNCHW-June-14, health workers distributed MNP at health centres as well as through outreach at churches, schools, temporary health posts, community centres and house-to-house, as they were concerned about a low attendance at their facilities.

\section{Training}

Training-of-trainers and capacity-building sessions were held prior to the MNCHW-Dec-13 for fifty State Ministry of Health and Local Government Area staff, and 840 staff of health centres implementing MNP distribution, and refresher trainings were held before the IPD-Mar-14 and MNCHW-June-14. This additional training module, integrated into the existing MNCHW and IPD curricula, was focused on child nutrition and MNP, their role in preventing anaemia and promoting child health and development, and how caregivers should use MNP for home fortification of semi-solid complementary foods. The MNCHW in Nigeria routinely include vitamin A supplementation, deworming, vaccinations and other health promotion services for children aged 6-59 months, as well as infant, antenatal and postpartum health promotion and services ${ }^{(8)}$, and Benue State Ministry of Health organizes IYCF support groups through Local Government Area-level nutrition focal points. The comprehensive BCC materials on IYCF were newly introduced with this MNP pilot.

Key components for delivery of micronutrient powders According to guidelines, MNP sachets were to be distributed to caregivers of all children 6-59 months of age, together with printed BCC materials, instruction on good nutrition and a recommendation to use two or three sachets per week. The entire contents of the sachet were to be added, after food preparation and at the time of serving, to a small portion of suitable, non-liquid food that the child can consume at one time.

\section{Advocacy, social mobilization and behaviour change} communication materials

The pilot was publicly launched during the MNCHWDec-13 by state policy leaders, followed by advocacy visits to community leaders and policy makers. BCC and social mobilization activities and materials were developed based on formative research preceding MNCHW-Dec-13 (group participatory methods and pre-testing of materials in selected pilot areas) conducted by the Center for Communication Program Nigeria. Messaging was developed around a tag-line 'Eat well, grow well', which was well received by health workers and targeted beneficiaries. Specific social mobilization and BCC activities were designed to include the following:

1. Distribution to health facilities and communities of 1000 posters, 5000 pamphlets and 5000 flyers across three local languages, before and during the MNP distribution events, explaining the importance of good child nutrition and the benefits and recommended use of MNP.

2. Road shows and rallies held by health workers for the general public throughout the 6-month pilot, mobilizing caregivers to pick up MNP.

3. Two hundred and eighty town announcers to mobilize caregivers to pick up MNP during the MNCHW and IPD, using a tailored MNP-centred guideline and manual.

4. Social/community outreach (dance, folksong and drama) events held before, during and after each distribution event by existing IYCF support groups of women volunteers trained by pilot staff. These events were held at community level for local caregivers and were intended to improve child nutrition knowledge and behaviours among parents and the use of MNP.

5. Group health talks and individual caregiver counselling about nutrition including MNP delivered by health workers at health facilities during the distribution events.

6. Opportunities for community dialogue, including demonstration sessions on how to add MNP to children's food, organized periodically at health centres during MNCHW, as time allowed.

\section{Evaluation design}

Of the five Local Government Areas involved in the pilot, four were evaluated, due to security challenges in one.

\section{Data collection and sampling}

Four main modes of survey data collection were used.

1. Two cross-sectional surveys were conducted among caregivers attending the first event (MNCHW-Dec-13) and/or second event (MNCHW-June-2014) with an eligible child. Questionnaires were administered to a stratified sample of caregivers at the facilities just prior to receiving services; they covered household demographic and socio-economic situation, and knowledge and feeding practices of the child attending, including use of MNP. At baseline, thirty-two of the 238 participating facilities were randomly selected. From the thirty-two facilities, 451 eligible caregiverchild pairs were randomly selected; a sample sufficient to detect a $10 \%$ reduction in anaemia prevalence (the pilot's impact target, reported elsewhere) from an estimated baseline prevalence of $50 \%(12)$, with $5 \%$ type 1 error, $80 \%$ power, a design effect of 2 , and adjusting for $15 \%$ expected drop-out. At baseline, this sample size was doubled for the questionnaire, as this would permit random selection of the 451 caregiverchild pairs that would agree to participate in the anaemia study. In the second MNCHW survey, twenty-nine of the thirty-two selected facilities were re-surveyed, while three that were no longer functional 
were replaced by another facility in the same Local Government Area; a sample of 534 caregiver-child pairs was adequate to detect a $50 \pm 6 \%$ prevalence of awareness of MNP with $5 \%$ type 1 error, $80 \%$ power and a design effect of 2.

2. A longitudinal cohort of mother-child pairs was surveyed during home visits following distribution events. Home visits were made 7 weeks after the MNCHW-Dec-13 and 4 weeks after the IPD-Mar-14 to ascertain MNP acceptability, use and adherence. This was done using structured questionnaires and review of self-monitoring cards, which had been given to the sample of caregivers selected for home visits at the MNCHW-Dec-13 with instruction to record the days that they used MNP for the eligible child. From a random sample of sixteen of the thirty-two surveyed facilities (four in each Local Government Area), a random sub-sample of 272 caregivers with a child 6-23 months of age at the time of the MNCHW-Dec-13 (seventeen per facility), who had been surveyed at the facility and who had received at least thirty MNP sachets, were selected. This sample could detect a change in MNP knowledge or correct use from $60 \%$ at baseline to $75 \%$ at endline (5\% type 1 error, $80 \%$ power, design effect of 2 and $15 \%$ drop-out rate).

3. A single cross-sectional survey of health worker knowledge was conducted 1 week before the MNCHW-June-14. Frontline workers who had participated in MNP distribution in the MNCHW-Dec-13 and/or IPD-Mar-14 and who would be trained at that occasion completed a self-administered questionnaire concerning their knowledge of MNP and their history of MNP distribution practice in the last 6 months.

4. Structured, facility-based observations were made for MNP and BCC material distribution, MNP counselling and health education, and routine recording in MNP registers and tally sheets, and recorded on checklists during the IPD-Mar-14 and MNCHW-June-14. Distributions in outreach activities done outside the clinics were not observed. For the IPD-Mar-14, eight health facilities were selected from each of the four Local Government Areas, plus five additional facilities from which the home cohort had been sampled in December (total $n$ 37). In the MNCHW-June-14, sixteen of the thirty-two facilities where the cross-sectional caregiver-child survey was conducted were randomly selected. These observations were made by the independent study team (Binomial Optimus Ltd), with oversight by GAIN.

Coverage of MNP was estimated in surveyed facilities based on post-distribution inventory reports and population data on the number of 6-59-month-old children in the area.

Enumerators were indigenous to Benue State, understood the local languages and culture, and $>90 \%$ had experience in survey data collection. Enumerators were trained for $3 \mathrm{~d}$ on IYCF, MNP, the evaluation objectives, subject eligibility and structured interviewing. Draft questionnaires, in three local languages, were validated and pre-tested at health centres, and revised. Supervisors checked questionnaires daily and any errors, missing responses and inconsistencies were resolved prior to data entry.

\section{Ethical clearance}

The study was conducted according to the guidelines laid down in the Declaration of Helsinki and all procedures involving human subjects were approved by the Benue State Ministry of Health. State and Local Government Area Health Department Heads and Chief Medical Officers of medical facilities involved also granted permission for surveys. Written informed consent was obtained from all participants.

\section{Data analysis}

Survey data were analysed using the statistical software package IBM SPSS Statistics version 22. Differences in responses between the first and second home visits were analysed using the independent Student $t$ test for continuous variables, the $\chi^{2}$ test for categorical variables and the normal distribution test of difference in proportions for proportional outcomes.

\section{Results}

Characteristics of caregivers and children reached Caregivers in the MNCHW-Dec-13 and MNCHW-June-14 facility-based surveys were similar in demographic and socio-economic characteristics (Table 1), while the caregivers in the post-MNCHW-Dec-13 home visit were more likely to report being farmers than in the second home visit. Children were younger in the MNCHW-Dec-13 sample than in the MNCHW-June-14, due to the prioritization of 6-23-month-old children in December in response to the initial shortage of MNP supply.

\section{Recruitment (social mobilization)}

Implementation of the planned social mobilization activities, the main way of recruiting participation in this programme, was incomplete. For example, the MNCHWJune-14 facility-based observations indicated that only $40 \%$ of facilities surveyed had an associated town announcer. As an indicator of the overall success of social mobilization for MNP, more than half of caregivers attending the MNCHW-Jun-14 had heard of MNP, up from $2 \%$ at the MNCHW-Dec-13 (Table 2).

\section{Fidelity (quality of Maternal, Neonatal and Child Health Week-based programme implementation)}

We used results covering health worker training and knowledge, and other facility-based observations of health worker participation, to describe programme fidelity with 
Table 1 Characteristics of caregivers surveyed in four Local Government Areas of Benue State, Nigeria

\begin{tabular}{|c|c|c|c|c|}
\hline & $\begin{array}{l}\text { MNCHW-Dec-13 facility- } \\
\text { based caregiver survey }\end{array}$ & $\begin{array}{l}\text { Home visit, post- } \\
\text { MNCHW-Dec-13 }\end{array}$ & $\begin{array}{l}\text { Home visit, post- } \\
\text { IPD-Mar-14 }\end{array}$ & $\begin{array}{l}\text { MNCHW-June-14 facility- } \\
\text { based caregiver survey }\end{array}$ \\
\hline Number of respondents & 896 & 237 & $129 \dagger$ & 578 \\
\hline \multicolumn{5}{|l|}{ Child age (months) } \\
\hline Mean & 16 & 13 & 14 & 21 \\
\hline \multirow[t]{2}{*}{ Range } & $6-59$ & $6-23$ & $6-23$ & $6-59$ \\
\hline & \multicolumn{4}{|c|}{$\%$} \\
\hline \multicolumn{5}{|l|}{ Household income (Naira/month) } \\
\hline$\leq 9999$ & $46 \cdot 9$ & $57 \cdot 4$ & 54.6 & $57 \cdot 8$ \\
\hline $10000-49999$ & $36 \cdot 9$ & 28.9 & $29 \cdot 6$ & $35 \cdot 0$ \\
\hline $50000-99999$ & $6 \cdot 1$ & $5 \cdot 3$ & $5 \cdot 6$ & 4.4 \\
\hline$\geq 100000$ & 1.7 & 1.9 & $2 \cdot 8$ & 1.8 \\
\hline Other & 4.3 & 1.5 & 3.7 & 0.0 \\
\hline Non-response & $4 \cdot 1$ & 4.9 & $3 \cdot 7$ & 1.0 \\
\hline Caregiver is a farmer & $56 \cdot 8$ & $71 \cdot 0$ & $49 \cdot 1 \ddagger$ & 55.7 \\
\hline $\begin{array}{l}\text { Caregiver has secondary education } \\
\text { or higher }\end{array}$ & $51 \cdot 0$ & $44 \cdot 9$ & $49 \cdot 0$ & $54 \cdot 0$ \\
\hline $\begin{array}{l}\text { Surveyed child aged } 6-23 \text { months } \\
\text { currently breast-feeding }\end{array}$ & $65 \cdot 8$ & $65 \cdot 1$ & $64 \cdot 0$ & 68.4 \\
\hline
\end{tabular}

MNCHW, Maternal, Neonatal and Child Health Weeks; IPD, Immunization Plus Days.

${ }^{*}$ As of December 2013, 160 Nigerian Nairas $=$ \$US 1.

tOnly 129 caregiver-child pairs $(47 \%)$ of the original 272-pair cohort were seen, with loss to follow-up in part due to displacements and communal crises. $\ddagger$ Significantly different from home visit post-MNCHW-Dec-13 at $P<0.01$.

Table 2 Health worker and caregiver knowledge of MNP and fidelity of MNP programme implementation in four Local Government Areas in Benue State, Nigeria

\begin{tabular}{|c|c|c|c|c|c|}
\hline Question (correct response) & $\begin{array}{l}\text { Health } \\
\text { worker } \\
\text { survey }\end{array}$ & $\begin{array}{l}\text { MNCHW-Dec-13 } \\
\text { facility-based } \\
\text { caregiver survey }\end{array}$ & $\begin{array}{l}\text { Home visit } \\
\text { post-MNCHW- } \\
\text { Dec-13 }\end{array}$ & $\begin{array}{l}\text { Home visit } \\
\text { post-IPD- } \\
\text { Mar-14 }\end{array}$ & $\begin{array}{c}\text { MNCHW-June-14 } \\
\text { facility-based caregiver } \\
\text { survey }\end{array}$ \\
\hline \multirow[t]{2}{*}{ Number of respondents } & 176 & 896 & 237 & $129 \dagger$ & 578 \\
\hline & \multicolumn{5}{|c|}{$\%$} \\
\hline Have you ever heard of MNP? (Yes)* & - & 1.7 & - & - & $54 \cdot 5$ \\
\hline $\begin{array}{l}\text { What is MNP? (Powder containing } 15 \\
\text { micronutrients) }\end{array}$ & 75 & - & - & - & - \\
\hline $\begin{array}{l}\text { What is MNP? (Sachet of vitamins and } \\
\text { minerals or Something added to the food of } \\
\text { young children) }\end{array}$ & - & - & 83 & $98 \ddagger$ & 95 \\
\hline $\begin{array}{l}\text { To what size/portion of food should MNP be } \\
\text { added? (Small portion a child can eat at a } \\
\text { time) }\end{array}$ & - & - & 92 & 96 & 88 \\
\hline \multicolumn{6}{|l|}{ To which foods can MNP be added? } \\
\hline $\begin{array}{l}\text { (Soft food, porridge, pap, mashed rice, } \\
\text { beans, yam, other solid or semi-solid foods) }\end{array}$ & 80 & - & 76 & 82 & 94 \\
\hline (Incorrect responses: milk, tea or liquids) & 14 & - & 30 & 11 & - \\
\hline $\begin{array}{l}\text { Should MNP be added to food while cooking or } \\
\text { hot? (No) }\end{array}$ & 69 & - & 92 & 85 & 81 \\
\hline $\begin{array}{l}\text { What is the minimum age targeted for MNP? } \\
\text { (6 months) }\end{array}$ & 76 & - & - & - & - \\
\hline $\begin{array}{l}\text { What is the maximum age targeted for MNP? } \\
\text { (59 months) }\end{array}$ & 8 & - & - & - & - \\
\hline $\begin{array}{l}\text { Health workers delivering correct number of } \\
\text { MNP sachets }\end{array}$ & 91 & - & - & - & - \\
\hline $\begin{array}{l}\text { Caregivers receiving correct number of MNP } \\
\text { sachets }\end{array}$ & - & - & 81 & 90 & - \\
\hline Caregivers reporting positive effects of MNP & - & - & 88 & $95 \ddagger$ & 84 \\
\hline Caregivers reporting negative effects of MNP & - & - & 31 & 33 & - \\
\hline
\end{tabular}

MNP, micronutrient powder; MNCHW, Maternal, Neonatal and Child Health Weeks; IPD, Immunization Plus Days.

${ }^{*}$ Responses for 'Have you ever heard of MNP?' were drawn from the full sample of 578 caregivers surveyed, while responses to questions about MNP use were limited to the 315 caregivers who reportedly picked up MNP at the MNCHW-Dec-13.

†Only 129 caregiver-child pairs (47\%) of the original 272-pair cohort were seen, with loss to follow-up in part due to displacements and communal crises. ¥Significantly different from home visit post-MNCHW-Dec-13 at $P<0.01$. 
respect to the quality of delivery of the programme. In all facilities, at least one health staff member was trained on MNP prior to the MNCHW-Dec-13. Quality of training varied between Local Government Areas and facilities. Refresher training was conducted among $84 \%$ and $72 \%$ of health facilities observed in the IPD-Mar-14 and MNCHW-June-14, respectively. At those distribution events, quality and frequency of counselling for both groups and individual caregivers varied within and among facilities, being generally acceptable in the early morning, but weakening through the day. Health worker knowledge retention was relatively high with regard to the content and correct use of MNP (Table 2). In contrast, however, very few could recall the correct maximum age of children targeted. Health workers in the majority of facilities (88\%) were observed to provide the correct number of sachets per child, corroborating the health worker survey results and caregiver responses in the home visits (Table 2).

Open observations at the facilities indicated that health workers were initially not well motivated to accept MNP distribution as an added task during $\mathrm{MNCHW}$, articulating work overload and inadequate financial compensation; some initially refused to participate and some exhibited passive aggressive behaviour. In some facilities, non-health staff members were recruited to provide services or record data. There was no standard process for providing corrective training prior to subsequent MNP distribution events.

\section{Dose delivered (distribution of micronutrient powders and implementation of behaviour change communication materials)}

Distribution of micronutrient powders

For the MNCHW-Dec-13, health facilities in the four Local Government Areas reported that a total of $2 \cdot 8$ million MNP sachets were distributed to an estimated 94600 children, based on an assumed thirty sachets per child. However, during on-site monitoring at the IPD-Mar-14 and MNCHW-June-14 distributions, the evaluation team observed that the facility-based records were erroneous. When MNP distribution and supply monitoring by the evaluation team was conducted more rigorously after the MNCHW-June-14 as a result of the previously identified health facility reporting errors, eight of the sixteen monitored facilities over-reported (by a mean of $35 \%$; range 6-240\%) and three under-reported (by a mean of $10 \%$; range $9-15 \%$ ), resulting in a net over-reporting of $8 \%$. The main reason for over-reporting was, as in both preceding distribution events, that facilities failed to adjust for MNP stocks left over after the distribution event. Therefore, the coverage data presented for MNCHW-Dec-13 (Table 3) were adjusted downwards by $8 \%$, while data for IPDMar-14 and MNCHW-June-14 take leftover MNP sachets into account based on the evaluator observations. Overall, the distribution of 8 million MNP sachets over three events had an estimated coverage of one-third to one-half of all children 6-59 months of age per event.

\section{Implementation of behaviour change communication materials}

Throughout the pilot, the availability and distribution of BCC materials was incomplete (Table 4). For the MNCHWDec-13, BCC material dissemination and community activities were delayed until mid-week, due to late delivery of materials from the production site through Local Government Area warehouses and to the health facilities. At the IPD-Mar-14, only a few facilities and fixed distribution posts had all BCC materials available, while at the MNCHW-June-14, nine of sixteen facilities monitored had not received any BCC materials and two facilities ran out before the week's end.

\section{Dose received (receipt of micronutrient powders and related behaviour change communication materials)}

Receipt of micronutrient powders

At the MNCHW-June-14, approximately one-third of caregivers interviewed reported to have received MNP at

Table 3 MNP distribution and coverage in four Local Government Areas of Benue State, Nigeria

\begin{tabular}{|c|c|c|c|c|c|c|}
\hline & \multirow{3}{*}{$\frac{\text { Sachets distributed }^{*}}{\text { Millions }}$} & \multirow{2}{*}{\multicolumn{2}{|c|}{$\begin{array}{l}\text { MNP sachets provided per child among } \\
\text { health centres }\end{array}$}} & \multicolumn{3}{|c|}{ Children 6-59 months of age covered $†$} \\
\hline & & & & \multicolumn{2}{|c|}{$\begin{array}{l}\text { Distribution } \\
\text { records* }\end{array}$} & \multirow{2}{*}{$\frac{\text { Facility-based caregiver survey }}{\%}$} \\
\hline & & Mean & Range & $n$ & $\%$ & \\
\hline MNCHW-Dec-13 & 2.6 & 30 & 15-90 & 87000 & 49 & $31 \ddagger$ \\
\hline IPD-Mar-14 & $2 \cdot 1$ & 31 & $15-60$ & 68000 & 38 & $31 \ddagger$ \\
\hline MNCHW-June-14 & $3 \cdot 3$ & 58 & 40-90 & 57000 & 32 & - \\
\hline Total & $8 \cdot 0$ & & & & & \\
\hline
\end{tabular}

MNP, micronutrient powder; MNCHW, Maternal, Neonatal and Child Health Weeks; IPD, Immunization Plus Days.

*Based on best estimates of MNP distributed as derived from health facility routine registers, with adjustments made to correct for register errors and leftover MNP sachets. For IPD-Mar-14 and MNCHW-June-14 the adjustments were based on evaluators' on-site verification of under- and over-reporting in thirty-seven and sixteen randomly sampled facilities, respectively; for the MNCHW-Dec-13, register data were adjusted downwards by $8 \%$ based on the net over-reporting observed at MNCHW-June-14.

†Coverage determined using projected populations by Benue State and Local Government Areas for 2014, based on the Nigeria 2006 Census, as the denominator ${ }^{(19)}$. fBased on population size $\mathrm{e}^{(19)}$, this corresponds to 55000 children. 
Table 4 Delivery (dose delivered) and receipt (dose received) of MNP-related BCC materials in four Local Government Areas of Benue State, Nigeria

\begin{tabular}{|c|c|c|c|c|c|}
\hline & $\begin{array}{l}\text { Facility-based } \\
\text { observation, } \\
\text { IPD-Mar-14 }\end{array}$ & $\begin{array}{l}\text { Facility-based } \\
\text { observation, } \\
\text { MNCHW-June-14 }\end{array}$ & $\begin{array}{l}\text { Health } \\
\text { worker } \\
\text { survey }\end{array}$ & $\begin{array}{l}\text { Home visit } \\
\text { post- } \\
\text { MNCHW- } \\
\text { Dec-13 }\end{array}$ & $\begin{array}{l}\text { Home visit } \\
\text { post-IPD- } \\
\text { Mar-14 }\end{array}$ \\
\hline \multirow[t]{2}{*}{ Number* } & 37 & 16 & 176 & 237 & $129 \S$ \\
\hline & \multicolumn{5}{|c|}{$\%$} \\
\hline Are there MNP posters on the walls of the health facilities? & 81 & $56+$ & - & - & - \\
\hline $\begin{array}{l}\text { Does the health worker give caregivers the MNP IEC/BCC } \\
\text { materials after receiving MNP? }\end{array}$ & 57 & 44 & - & - & - \\
\hline $\begin{array}{l}\text { Did you give leaflets about MNP to caregivers alongside } \\
\text { their MNP during March IPD? }\end{array}$ & - & - & $\begin{array}{l}\text { To all: } 25 \\
\text { To some: } 23\end{array}$ & - & - \\
\hline Have you ever been given an MNP leaflet? & - & - & - & 15 & $36 \|$ \\
\hline $\begin{array}{l}\text { The facility gave one or more group-based health talks on } \\
\text { MNP to mothers/caregivers on the day of observation }\end{array}$ & 73 & 69 & - & - & - \\
\hline $\begin{array}{l}\text { Are mothers/caregivers being reminded how to use the } \\
\text { MNP at home?/Did you explain to all caregivers how to } \\
\text { use MNP? }\end{array}$ & 73 & $94 \ddagger$ & $\begin{array}{l}\text { To all: } 66 \\
\text { To some: } 20 \\
\text { Sometimes, } \\
\text { if time: } 3\end{array}$ & - & - \\
\hline $\begin{array}{l}\text { Did a health facility staff ever give you information/ } \\
\text { education about MNP? }\end{array}$ & - & - & - & 73 & 92॥ \\
\hline $\begin{array}{l}\text { Have you received information about MNP by attending a } \\
\text { community meeting led by a community health worker } \\
\text { or IYCF support group? }\end{array}$ & - & - & - & 15 & 8 \\
\hline $\begin{array}{l}\text { Does the health worker tell the parents/caregiver when to } \\
\text { bring the child again for the next batch of MNP? }\end{array}$ & 11 & $56 \dagger$ & 20 & - & - \\
\hline $\begin{array}{l}\text { Did anyone remind you to go back and pick up the next } \\
\text { batch of MNP? }\end{array}$ & - & - & - & 74 & 78 \\
\hline
\end{tabular}

MNP, micronutrient powder; BCC, behaviour change communication; IPD, Immunization Plus Days; MNCHW, Maternal, Neonatal and Child Health Weeks; IEC, information, education and communication; IYCF, infant and young child feeding.

${ }^{*}$ Number of facilities for facility-based observations; or number of health workers or caregivers.

†Significantly different from IPD-Mar-14 at $P<0.01$.

¥Significantly different from IPD-Mar-14 at $P<0.05$.

§Only 129 mother-child pairs (47\%) of the original 272-pair cohort were seen, with loss to follow-up in part due to displacements and communal crises.

IISignificantly different from home visit post-MNCHW-Dec-13 at $P<0.01$.

the MNCHW-Dec-13 and IPD-Mar-14 events (Table 3), consistent with the adjusted coverage data for doses delivered.

\section{Receipt of behaviour change communication materials Caregiver reports at the home visits and in the MNCHW- June-14 survey indicated very limited receipt of BCC materials but higher exposure to MNP-related counselling at the distribution events, corroborating results from the health worker survey and facility-based observations (Table 4). Among the caregivers in the home visits, very few had received information about MNP when attending a community meeting led by a community health worker or IYCF support group. \\ Caregivers' knowledge, acceptance, use and adberence}

Caregiver knowledge of key aspects of MNP and their use was relatively high, whereby the majority could correctly state what MNP are and to what size/portion and type of foods MNP should be added (Table 2). Nevertheless, $30 \%$ of caregivers in home visits incorrectly stated that MNP can be added to milk or other liquids; this was true among $14 \%$ of health workers as well.
Most caregivers perceived positive effects of MNP on their child's health, while several also perceived some negative effects (Table 2). Positive effects mentioned included increased appetite (46-53\%), makes child stronger (39-46\%), increased energy and activity (32-38\%), makes child healthy (32\%) and increased immunity/less sickness (12-28\%). Negative effects most often mentioned were loose stools (2-13\%), black stools (0-8\%) and vomiting (3-6\%).

Most of the caregivers who received MNP reported to have used them for the targeted child (Fig. 1(a)). Among caregivers at home visits who indicated using the MNP, $69 \%$ post-MNCHW-Dec-13 reported giving MNP to the targeted child two or three times in the last week, consistent with health worker recommendations (Fig. 1(b)); however, this declined to $51 \%$ at the post-IPD-Mar-14 home visit. A similar trend was observed when asked to recall MNP use in the last $24 \mathrm{~h}$ (Fig. 1(c)). The median cumulative number of MNP sachets used over the first 7 weeks since the MNCHW-Dec-13 was 22 (range 0-49; Fig. 1(d)), representing an average use of 3 sachets per week. This corroborated well against self-monitoring cards, where caregivers recorded a median of 20 (range 1-44) d with MNP use, and against the evaluator observations of a 
(a)

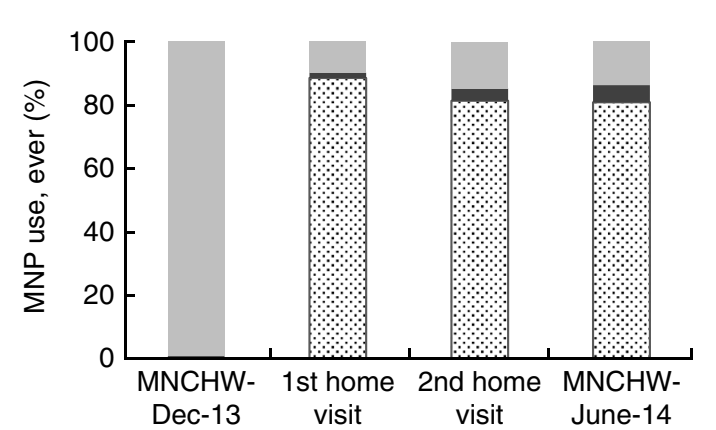

(c)

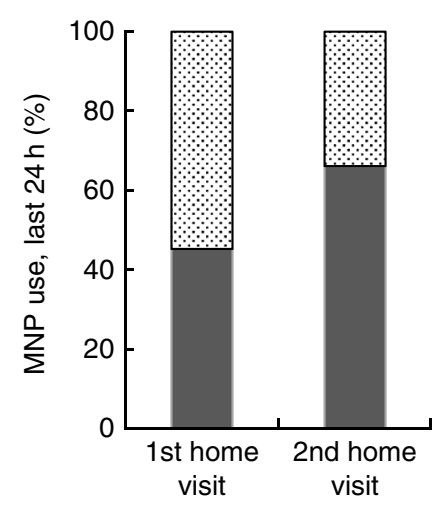

(d)

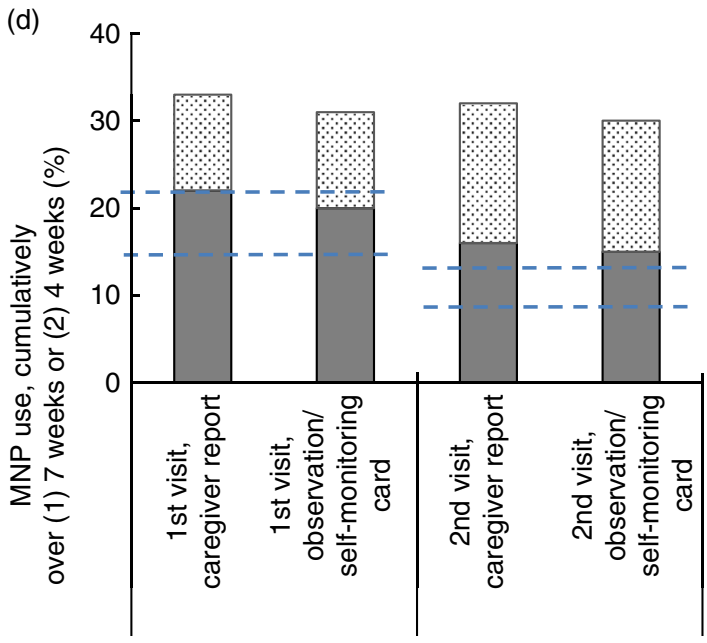

Fig. 1 Caregiver-reported frequency of MNP use* among children aged 6-23 months, in four Local Government Areas of Benue State, Nigeria: (a) ever used ( , no response; $\square$, received MNP, but never used; 9 , ever used MNP); (b) use during last 7 d ( $\square$, 4-7 times; $\square$, 2-3 times; 0,1 time; $\square$, never); (c) use during last $24 \mathrm{~h}$ ( (d) cumulative use (圆, sachets remaining; $\square$, sachets consumed). ${ }^{*}$ In (a) the denominators are: MNCHW-Dec-13, all children whose caregiver was surveyed ( $n$ 896); for home visits, all children participating in home visits and who had received MNP at MNCHW-Dec-13 ( $n 237$ in the post-MNCHW-Dec-13 visit and $n 129$ in the post-IPD-Mar-14 visit); for MNCHW-June-14, the subset of children whose caregiver was surveyed and reported having picked up MNP at the IPD-Mar-14 ( $n$ 110). In (b), (c) and (d), the denominator is children participating in the home visit cohort, all of whom had received MNP at the MNCHW-Dec-13, excluding non-responders; for (b) $n 196$ and $n 92$ for the post-MNCHW-Dec-13 and post-MNCHW-June-14 home visits, respectively; and for (c) $n 219$ and $n 115$ for the post-MNCHW-Dec-13 and post-MNCHW-Dec-13 home visits, respectively. In (d), per the recommended usage of 2-3 sachets per week, the cumulative usage over the 7 weeks since the MNCHW-Dec-13 should range from 14 to 21 and cumulative usage over the 4 weeks since the IPD-Mar-14 should range from 8 to 12, as indicated by the dashed line (- - -). In (a), non-response includes 'refuse to answer' as well as 'missing' (MNP, micronutrient powder; MNCHW, Maternal, Neonatal and Child Health Weeks; IPD, Immunization Plus Days)

median of eleven unused sachets remaining from the thirty received. Median MNP use was somewhat less frequent at the home visit after the IPD-Mar-14 (Fig. 1(b) and (c)).

\section{Context}

The MNP pilot distribution occurred in the context of marked socio-political insecurity that increased over the 6-month period and subsided just a few weeks before the June MNCHW. Attacks by local militia displaced thousands of households. Several health facilities in the four Local Government Areas were vandalized and closed, and fifteen facilities in three Local Government Areas were burnt down. Benue furthermore experienced two cholera epidemics between January and June 2014, further burdening health services' functions.

\section{Discussion}

This first-ever MNP distribution in Nigeria, piloting MNCHW as a delivery channel, found a high level of acceptance and use of MNP among caregivers and their beneficiary children, although at a lower population-level coverage than targeted. Initial shortage of MNP supply was overcome and, despite initial resistance among health workers to add MNP to the large package of services already provided during the MNCHW, health worker 
performance during distribution activities was largely found to be acceptable. Some deficiencies in health worker knowledge on specific aspects of MNP delivery and use, and incomplete implementation of all planned BCC and social mobilization activities, were noted for further strengthening.

Attained coverage for MNP was estimated to reach just over 30\% among children 6-59 months of age in the evaluated pilot area. Since the coverage data from the MNCHW-Dec-14 were adjusted only retrospectively for register errors, it is possible that the $49 \%$ coverage is still an overestimate. Among eligible caregiver-child pairs at the distribution events, only about one-third reported to have attended the previous MNCHW and picked up MNP. While we did not attempt to estimate the total number of caregivers with eligible children who attended these events, the results suggest that many caregivers do not attend all MNCHW or IPD events. This low level of coverage is similar to that observed for other services delivered mainly through MNCHW in Nigeria. In Benue State in 2013, approximately $20 \%$ of children $12-23$ months of age had received all basic vaccinations, $29 \%$ and $42 \%$ had received their third dose of DPT (diphtheria, pertussis and tetanus) and polio vaccinations, respectively, and $35 \%$ of children aged 6-59 months had reportedly received a vitamin A supplement in the past 6 months - slightly lower than the national averages ${ }^{(13)}$. Therefore, although coverage with MNP was not as high as routine planning targets and facility-based records would suggest, it does reflect the coverage achieved by MNCHW and IPD events in this population; the planning target of $50 \%$ coverage for MNP may have been over-ambitious and possibly resulting from the tendency to over-report health commodities distributed, as observed in this evaluation.

There were several shortfalls in the fidelity of programme implementation compared with the original design. Following the initial training, refresher training for subsequent distribution events was incomplete. This, together with initial resistance among health workers to add MNP to the MNCHW services already provided, likely related to their pre-existing high workload, may account for some limitations in health worker knowledge with respect to appropriate use and targeting of MNP. The initial shortage of MNP was overcome by including MNP delivery in the additional IPD event and this may be a useful approach to maintain moving forward. The inadequate delivery and receipt of BCC materials during distribution events is largely, but not entirely, attributed to the limited supply reaching the health facilities, reflecting a need to strengthen procurement and supply systems in support of MNP and other health commodity distribution.

Resources for social mobilization activities also fell short, and their planning and implementation were not fully transferred from the initiating organization to local health staff. A community mobilization platform going beyond MNCHW structures - for example integrating MNP communication into existing social mobilization for IPD, or social marketing approaches - might improve effectiveness, save costs and possibly increase support from Local Government Area officials, religious and traditional institutions, and other local organizations. The challenges observed here, however, were not unique to this pilot programme. An evaluation of MNCHW performance in Rivers State, Nigeria, in 2012 also revealed low rates (29\%) of awareness of the event, a coverage of $<25 \%$ and short supply of health commodities ${ }^{(14)}$. Procurement problems for MNP and BCC materials, the timeliness, intensity and effectiveness of social marketing, limited capacity to ensure fidelity with BCC protocols and lack of a monitoring process have also been reported in other MNP pilots and programmes regardless of the distribution model used ${ }^{(3,15,16)}$.

Despite the latter shortcomings, once caregivers received the MNP, these were generally well accepted, consistent with reports from other studies ${ }^{(17)}$, and among users, the recommendation to provide MNP two or three times per week was generally adhered to. Our results should be interpreted with some caution, however, as the facility-based and home-visit survey samples were drawn from caregivers already motivated to attend the MNCHW or IPD events and their level of knowledge, acceptance, use and adherence of MNP may not be representative of the general population. Established MNP programmes more commonly deliver MNP on a monthly basis, thus providing a regular supply and more frequent contact to reinforce their use, while few programmes to date are delivering MNP during periodic health facility events ${ }^{(16)}$. The current pilot study demonstrated that, among recipients, the less frequent point of contact for MNP and related BCC was still a feasible approach for achieving programme goals for MNP use. Nevertheless, some variation in acceptability and use was observed, including a small number reporting not using the MNP received and negative health effects. An apparent decline in MNP use between home visits may suggest that long-term adherence was declining, although this should be interpreted with caution given the reduced sample size in the second home visit. Overall, these results suggest that improving the intensity and frequency of BCC activities is still required to increase acceptance, use and sustained adherence. This should include the printing of information about MNP dosage and use directly on the sachet labels.

Limitations of the present process evaluation include suboptimal data quality available from the health system records for estimating MNP coverage. Since MNP distribution was not monitored in MNCHW-Dec-13 and was monitored within facilities but not during outreach, it is possible that sachets were distributed at a lower number per child and across a larger number of children, or conversely across fewer children at a higher number per child, than assumed in those cases. The possibility of some children receiving MNP twice in one distribution period cannot be excluded, particularly at the IPD-Mar-14 where 
the protocol of marking children after immunization, with or without MNP, was not strictly followed. While the pilot's beneficiary population was generally representative of Benue State in terms of women's education, occupation, breast-feeding patterns and IYCF practices ${ }^{(13,18)}$, the second home visit covered only $47 \%$ of the eligible cohort due to the difficult situation in these areas and the home visits themselves, including the use of self-monitoring cards, may have improved MNP use and potentially compromised representativeness of the home visit results. Should this pilot programme be expanded to other areas, it will be important to implement evaluations in a random sample of households to confirm the appropriate use of MNP and address reasons for suboptimal use. Finally, it is noteworthy that the pilot's implementation process, context and results varied somewhat across the four Local Government Areas, but for simplicity, the current paper presented only pooled results for all locations.

The main limitations to greater coverage of MNP through the MNCHW distribution model lie with the need for overall strengthening of the MNCHW system, the ability to increase attendance at these events, and the appropriate training and motivation for health workers to absorb this additional service. For scaling-up MNP distribution in Benue and Nigeria, the pilot's results justify further consideration of periodic MNCHW and IPD as one option that would offer sustainability given that these are well-established, publicly funded programmes. Of note, the pilot IPD achieved similar MNP coverage to MNCHW, and IPD offers an existing social mobilization platform onto which MNP-targeted communication might be tagged. Alternative or complementary public delivery channels could include the routine (continuous) facility-based immunization services - which over time might achieve equally high or higher coverage than the 6-monthly health events. Health facilities were the preferred channel for MNP pick-up for $85 \%$ of caregivers interviewed in this pilot. Finally, subsidized or fully commercial sales might be an option for wealthier Southern states that have widespread access to retail stores.

\section{Conclusion}

In conclusion, MNP distribution through MNCHW achieved coverage and use by Nigerian children in line with coverage achieved for other services delivered through MNCHW. For a pilot launching MNP production, distribution and MNP-tailored mobilization in-country for the first time, and considering unforeseen security challenges, this is an encouraging result, inviting further evaluation in Benue and other Nigerian states. Structural challenges that limited the effectiveness of an already burdened MNCHW will, however, require health system strengthening beyond the scope of MNP distribution, as well as innovative approaches to social mobilization. The effectiveness and cost-effectiveness of MNCHW-based MNP distribution in reducing micronutrient deficiency and childhood illness remain to be evaluated and compared with alternative or complementary public and private delivery systems.

\section{Acknowledgements}

Acknowledgements: The authors thank the health workers, mothers and children who participated in the surveys and home visits. They thank Dr Orduen Abunku, the Honorable Commissioner for Health of Benue State, and Dr Joseph Kumba, Director Primary Health Care of Benue State, Ministry of Health. Behavioural change and social mobilization activities, data collection and analysis were supported by the Global Alliance for Improved Nutrition (GAIN). The authors thank Dr Dominic Schofield for his support in conceiving the pilot and Dr Lynnette Neufeld for advice on the manuscript. Financial support: This work was supported by the Bill and Melinda Gates Foundation (grant number 42564). The funder had no role in the design, analysis or writing of this article. Conflict of interest: None. Authorship: F.Am., F.Ad. and E.L.K. designed the study; F.Ad., O.A., C.A. and C.O. collected the data; O.A., F.Ad., A.A. E.L.K. and F.Am. analysed the results; E.L.K. and C.H. drafted the manuscript; E.L.K., O.A., F.Ad., A.A., C.A., C.O., C.H., L.U. and F.Am. contributed to the interpretation of results. All authors read and approved the final manuscript. Ethics of buman subject participation: The study was conducted according to guidelines laid down in the Declaration of Helsinki. All procedures involving human subjects were approved by the Benue State Ministry of Health.

\section{References}

1. Bhutta ZA, Das JK, Rizvi A et al. (2013) Evidence-based interventions for improvement of maternal and child nutrition: what can be done and at what cost? Lancet 382, 452-477.

2. De-Regil LM, Suchdev PS, Vist GE et al. (2013) Home fortification of foods with multiple micronutrient powders for health and nutrition in children under two years of age (Review). Evid Based Child Health 8, 112-201.

3. Rah JH, dePee S, Kraemer K et al. (2012) Program experience with micronutrient powders and current evidence. J Nutr 142, issue 1, 191S-196S

4. Suchdev PS, Ruth LJ, Woodruff BA et al. (2012) Selling Sprinkles micronutrient powder reduces anemia, iron deficiency, and vitamin A deficiency in young children in Western Kenya: a cluster-randomized controlled trial. Am J Clin Nutr 95, 1223-1230.

5. Sun J, Dai Y, Zhang S et al. (2011) Implementation of a programme to market a complementary food supplement (Ying Yang Bao) and impacts on anaemia and feeding practices in Shanxi, China. Matern Child Nutr 7, Suppl. 3, 96-111.

6. Hirve S, Martini E, Juvekar SK et al. (2013) Delivering Sprinkles Plus through the Integrated Child Development Services (ICDS) to reduce anemia in pre-school children in India. Indian J Pediatr 80, 990-995.

7. Palmer AC, Diaz T, Noordam AC et al. (2013) Evolution of the child health day strategy for the integrated delivery of child health and nutrition services. Food Nutr Bull 34, 412-419. 
8. Federal Government of Nigeria, National Primary Health Care Development Agency (2014) Guidelines for Implementing Maternal, Newborn and Child Health Week in Nigeria, 2nd ed. Abuja: Federal Government of Nigeria.

9. Nigeria Federal Ministry of Health, Department of Family Health, Nutrition Division (2013) National Guidelines on Micronutrient Deficiencies Control in Nigeria. Abuja: Nigeria Federal Ministry of Health.

10. Saunders RP, Evans MH \& Joshi P (2005) Developing a process-evaluation plan for assessing health promotion program implementation: a how-to guide. Health Promot Pract 6, 134-147.

11. Sunley Consulting (2013) Report of an Evaluation of Formulation, Process and Quality Control Requirements for MNP Production at Bio-Organics, Lagos, Nigeria. Lagos: Sunley Consulting for the Global Alliance for Improved Nutrition.

12. World Health Organization (2009) Worldwide Prevalence of Anaemia 1993-2005, WHO Global Database on Anaemia. Geneva: WHO.

13. Nigeria National Population Commission \& ICF International (2014) Nigeria Demographic and Health Survey
2013 - Final Report. Abuja and Rockville, MD: NPC and ICF International.

14. Ordinioha B (2013) How effective is the 2012 maternal, newborn and child health week (MNCHW) in Rivers state? Nigerian Health J 13, 33-39.

15. Kodish S, Rah JH, Kraemer K et al. (2011) Understanding low usage of micronutrient powder in the Kakuma Refugee Camp, Kenya: findings from a qualitative study. Food Nutr Bull 32, 292-303.

16. Jefferds ME, Irizarry L, Timmer A et al. (2013) UNICEF-CDC global assessment of home fortification interventions 2011: current status, new directions, and implications for policy and programmatic guidance. Food Nutr Bull 34, 434-443.

17. Dewey KG, Yang Z \& Boy E (2009) Systematic review and meta-analysis of home fortification of complementary foods. Matern Child Nutr 5, 283-321.

18. Nigeria National Population Commission \& ICF International (2009) Nigeria Demographic and Health Survey 2008 - Final Report. Abuja and Rockville, MD: NPC and ICF International.

19. Nigeria Population Commission (2007) Census 2006 National and State Population and Housing Tables: 2006 Census Priority Tables. Abuja: NPC. 